\title{
Sharing the Secret Sauce
}

\section{Engaging Early Childhood Educators in Library Storytime Practices}

LORI ROMERO AND LAURIE ANNE ARMSTRONG

$\mathrm{I}$ f you peek into Kirsten's preschool classroom in suburban Denver early on a Tuesday morning, you'll quickly notice that the eager three-year-olds are not the only ones enthusiastically singing, "Go Bananas!"

The students bring up flannelboard pieces for Karen Beaumont's Dini Dinosaur while answering, "What do you think will happen next?" In another story, Ding Dong Gorilla by Nicola O'Byrne, Kirsten and her children gather around the "library lady" who is visiting the classroom.

Kirsten knows she is in for a treat from Arapahoe Libraries early literacy trainer, Laurie Anne, who shares a love for books while reading a fun story for the children. Laurie Anne also strategically models ways for Kirsten to build vocabulary, background, and print knowledge.

During the storytime, Laurie Anne skillfully pauses to directly address the teacher: "Kirsten, notice how engaged the children become when I ask open-ended questions and give them time to think and answer. That's exactly how we develop comprehension."
Kirsten knows that the Reading Readiness Outreach program will help her understand the "why" behind the strategies and materials that are shared each time she receives a visit. She also knows that written tips and a practice kit will be left with her, and that the trainer will return to her classroom to help make it all stick! Through these encounters, Kirsten gains a mentor, support, and partner in early literacy. These are the perfect ingredients for reading readiness.

\section{Our Story}

Early childhood literacy is certainly a hot topic in libraries throughout the country, and for good reason. According to the National Kids Count 2015 report, 65 percent of children at the end of third grade are reading below proficient levels. ${ }^{1}$ Intervention in the early years of a child's development is critical to changing that dynamic.

According to the Center for the Developing Child at Harvard University, "Early environments and experiences have an especially strong influence on brain architecture." ${ }^{2}$ The Arapahoe Libraries believes we can have a great impact on education in

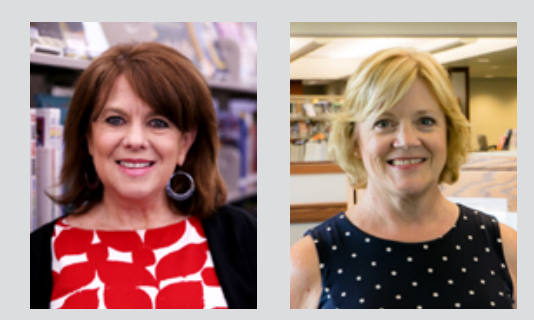

Reading specialist Lori Romero, MA, Ed, is the coordinator and supervisor of the Child \& Family Library Services department for the Arapahoe Libraries in Colorado. Laurie Anne Armstrong, MA, Ed, a former preschool educator, is an early literacy trainer for the Arapahoe Libraries. 


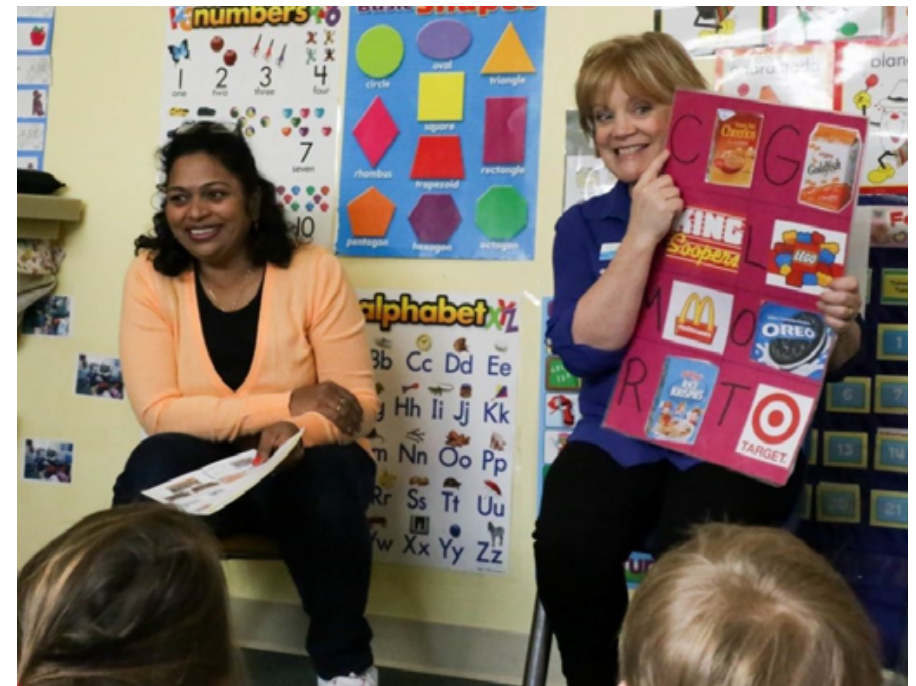

Laurie Anne and a classroom teacher collaborate during storytime.

the early years so that children are not at risk of falling behind by the time they start kindergarten.

Arapahoe Libraries is determined to be "all in" when it comes to setting the stage for children in the community to be motivated and ready to learn to read when they enter kindergarten. That means a strong library commitment to early literacy in eight libraries and on our bookmobile.

Is there a better early literacy resource and platform for reaching caregivers and young children than storytime-based programs at the library? We don't think so!

We realized, however, that we can also spread the early literacy message to adults who are directly involved in young children's lives outside the library walls. We recognized the potential to reach audiences who are unfamiliar with library storytimes or don't have access to a local library.

In our planning stage, we spent time in several early childhood settings where teachers see young children every day. It became clear that supporting preschool educators in a deeper, more intentional way through storytime could be the catalyst needed to jumpstart an early literacy ripple effect in our community. The Reading Readiness Outreach Program was born. The focus? Teachers.

In coordination with our state preschool learning guidelines, Reading Readiness Outreach work is grounded in the skills and practices outlined in the research-based Every Child Ready to Read (ECRR) ${ }^{3}$ initiative. The library's early literacy trainer demonstrates effective strategies for reading, singing, playing, talking, and writing with preschool teachers in a way that makes an empowering and lasting mark. These teachers are deepening their understanding and refining techniques for turning everyday moments throughout a preschooler's day into powerful literacy experiences, beginning with effective literacy-based storytimes.

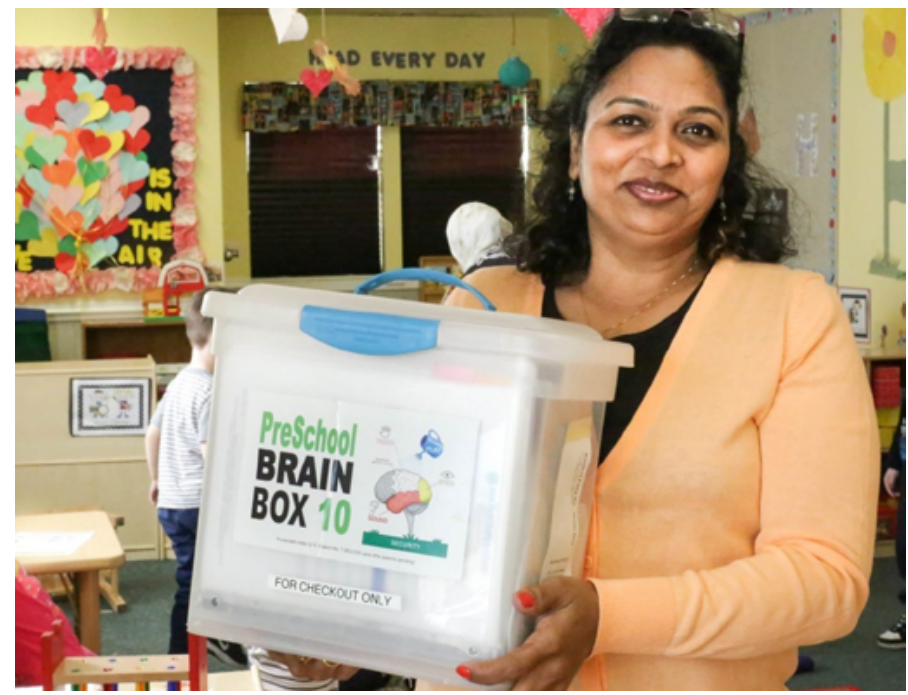

Classroom teachers now use library materials and resources regularly.

Laurie Anne currently works with fifty-one teachers in eight preschools. Arapahoe Libraries took deliberate steps to make sure we were hitting the mark by targeting sites with the highest needs.

Since there are many preschools within in our library service area, we had to limit our scope while maximizing our effect in the community. We developed a matrix that considers teacher education and experience along with reading test scores and free/reduced lunch data at nearby elementary schools. Armed with this information, and an established relationship with the preschool site director, we began working with both teachers and families in the chosen locations. Our goal? To bring powerful and intentional school-library-home early literacy connections to the table for a winning initiative.

\section{Making School Connections}

To be clear about the program's scope, it was important to have a defined early literacy curriculum based on ECRR skills and practices. The early literacy trainer's role is enhancing teachers' expertise in promoting early literacy. Along with an all-staff training, we ask each participating teacher to take a short presurvey about their background knowledge.

Our trainer then visits the classrooms and observes the teachers' storytimes, revealing their strengths and exposing areas that need support through modeling, coaching, and follow-up conversations.

After the initial observation, our trainer then begins providing storytime demonstrations and having conversations in designated classrooms twice a month. She chats with teachers oneon-one, and leaves printed tip sheets that include book titles and songs. She also leaves practice materials in a kit, including a copy of the picture book modeled during storytime. 


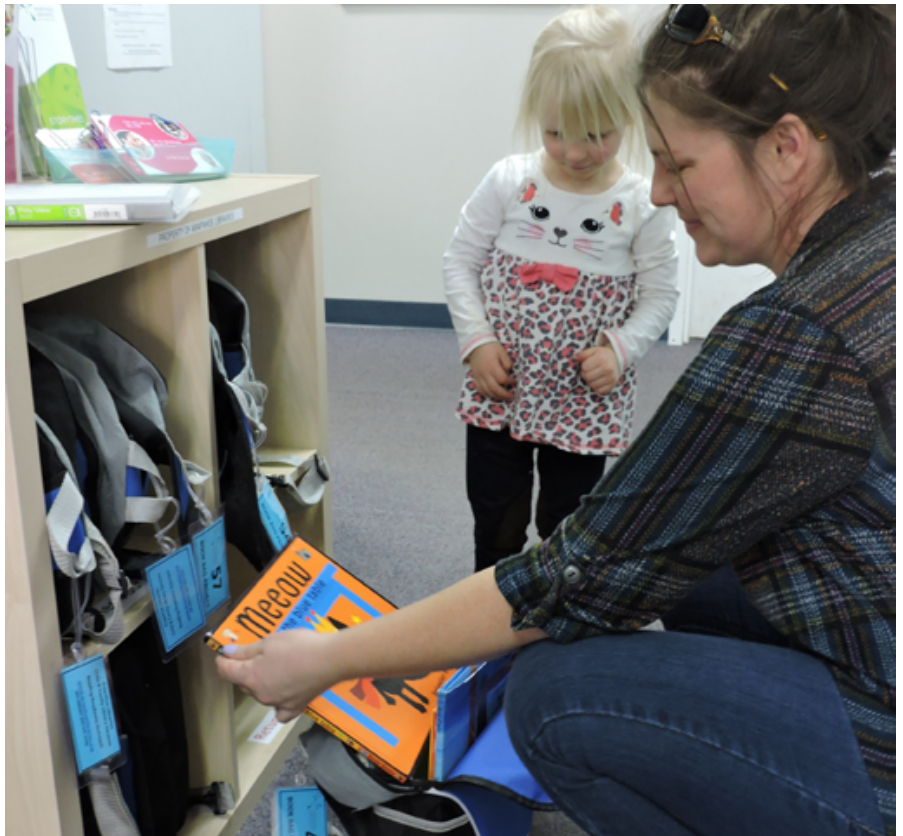

A parent and child check out book bags to share at home.

Laurieanne is frequently delighted at follow-up visits because enthusiastic teachers and kids can't wait to share. After she had demonstrated using objects in a box as props for storytelling, the children and teacher were excited to show her that they had made their own storytelling boxes later in class!

Another teacher excitedly remarked, "I remembered you teaching me that adding motions along with singing a song helps kids remember the words, and I have noticed the kids are asking to sing more and more often!"

Finally, one teacher showed Laurie Anne a great follow-up activity she and the children had done a few days after an introduction to the book I Love Cake by Tammi Sauer. They had baked a cake and created recipe books!

Laurie Anne sings the teachers' praises to the directors, keeping them in the loop about the growth she's documenting and shares what to look for as they supervise and evaluate their staff.

\section{Making Library Connections}

After realizing many of the teachers and directors had never been to the library before, we invited them to take a field trip to the library for a kick-off overview event. The Arapahoe Libraries early literacy team introduces the Reading Readiness Outreach program, issues library cards, demonstrates using the website, and provides a library tour to highlight materials, resources, and services for teachers to use. The effect of adding this component has been tremendous. Suddenly, more teachers are becoming library users.

Preschool teachers have begun showing our trainer the materials they are checking out to use in their classrooms each day and have mentioned they had no idea that the library has so many resources for teachers. It's clear how much the staff appreciates these off-site experiences.

\section{Making Home Connections}

The ripple effect of the program is strongest, of course, if parents are aware of what's happening at preschool and can follow up at home. We aim to build relationships and support for families as they get their children ready to learn to read.

First, a strong home connection was made when we began providing circulating book bags at preschools as a part of the Reading Readiness Outreach program. We purchased an inexpensive shelf for entry ways where families now gain access to motivating, age-appropriate books along with library information. The circulation of the book bags has tripled, and more families have begun to come to the library.

Second, each time our trainer visits and models early literacy skills for teachers, she also provides a handout for parents and caregivers. The handout includes early literacy tips, book titles, words to songs or fingerplays, and practical ideas.

Finally, a home-library connection is built with the preschool community because we attend family festivals, literacy nights, and informally meet parents during pick-up times. We are thrilled to promote library programs and resources, and parents are excited to see an enthusiastic face from the library partnering with their school.

\section{What's Next?}

The next leg of our journey is solidifying program outcomes. We now provide progress check points, along with pre- and post-storytime observations and surveys reflecting teachers' knowledge about early literacy skills. In addition, we are capturing anecdotal success stories throughout the program that can be shared with library board members and stakeholders in the community.

One preschool director says she realizes that it is so very important for her teaching staff to have a practical understanding of early literacy skills and the ability to apply these skills daily in their classrooms. She now includes questions about early literacy when interviewing prospective teachers.

To the director's amazement, the preschool teachers she has interviewed have had limited knowledge they could share with her. She knows the Reading Readiness Outreach program will be invaluable as she trains new hires.

Laurie Anne gives a first-hand account of the improvement one of her teachers has made:

When Sarah and I first began working together, she was struggling with fostering conversation and participation 
during storytime. After several visits modeling, coaching, and practicing, she has made remarkable progress. The children are excited and engaged, and are now being allowed to contribute ideas and ask questions throughout storytime. Sarah does a nice job balancing reading and asking open ended questions while listening and responding to the children. The teacher, Sarah, also commented, "The Reading Readiness program has made a huge difference in my planning for storytime and incorporating literacy into daily activities. I now use songs and fingerplays during transition times and leave flannelboard storyties and puppets out for children to retell stories."

\section{Adding the Secret Sauce}

Storytimes are indeed magical and feed minds, hearts, and bodies in libraries from coast to coast. Many children's librarians are equipped and on the lookout for opportunities to take the storytime show on the road through preschool and community outreach.

While this is important and wonderful, at the Arapahoe Libraries, we wanted to take an extra step. With our goal of supporting every child's early literacy success in mind, we hoped that adding an ongoing and focused staff development plan for early childhood educators could be the "secret sauce" that makes the difference for far-reaching success. The Reading Readiness Outreach Program was designed to share early literacy strategies with targeted early childhood educators outside the library.

Our early literacy trainer works hard to develop trust and strong relationships with teachers, directors, and families at preschool sites. Her passion is very clear. She dives in by inviting teachers to the library, modeling effective storytime techniques, being present for parents at events, and fostering consistent reflection with early learning providers throughout the year.

The Reading Readiness Outreach Program is bringing the library to preschools in a big way, and we believe this partnership of school, library, and home is a connection that will improve school readiness and help create lifelong readers.

Want to get started? Review your library's strategic plan. Consider whether your early literacy goals are aligned with your library's vision. Start small. Most youth services staff have at least one person who is knowledgeable and passionate about early literacy, storytimes, and ECRR, and can share valuable information about your library.

Connect with a preschool site and together discuss the kinds of specific support you might offer. Your library's commitment to early literacy, a manageable plan, and willingness to make friends outside of the library will give your program credibility and staying power! $\measuredangle$.

\section{References and Note}

1. "Fourth Grade Reading Achievement Levels," Kids Count Data Center, last modified November 2015, http: / / data center.kidscount.org/data/tables/5116-fourth-grade -reading-achievement-levels\#detailed.

2. National Scientific Council on the Developing Child, "The Timing and Quality of Early Experiences Combine to Shape Brain Architecture," working paper, Center on the Develping Child, Harvard University, February 2008, http://46y5eh11fhgw3ve3ytpwxt9r.wpengine.netdna-cdn .com/wp-content/uploads/2007/05/Timing_Quality _Early_Experiences-1.pdf.

3. Every Child Ready to Read is a project of the Association for Library Service to Children (ALSC) and the Public Library Association (PLA), divisions of the American Library Association. ALSC and PLA have developed early literacy materials and programs to help every child become a successful reader. See http:/ / www.every childreadytoread.org/. 